comments thus add further weight to the original observations of Baastrup et al.

Doubts regarding the true cause of the clinical events in Cohen \& Cohen's patients will never be completely resolved, although the validity of their own postulate of a lithium/haloperidol interaction seems to be diminishing as the full explanation.

M. R. LOWE

Basildon Hospital

Basildon, Essex

Janssen Pharmaceutical Ltd

Wantage

\section{H. BATCHELOR}

\section{Roferences}

COHEN, W. J. \& COHEN, N. H. (1974) Lithium carbonate, haloperidol and irreversible brain damage. Journal of the American Medical Association, 230, 1283-1287.

SCHOU, M. (1984) Long-lasting neurological sequelae after lithium intoxication. Acta Psychiatrica Scandinavica, 70, 594-602.

GOLDNEY, R. D. \& SPENCE, N. D. (1986) Safety of the combination of lithium and neuroleptic drugs. American Journal of Psychiatry. $143,882-886$.

Banstrup, P. C., Hollnaca, P., Sorensen, R. \& Schou, M. (1976) Adverse reactions in treatment with lithium carbonate and haloperidol. Journal of the American Medical Association. 236, 2645-2646.

\section{Tuberous Sclerosis and the Autistic Syndrome}

SIR: Lawlor \& Maurer (Journal, March 1987, 150, 396-397) described tuberous sclerosis presenting with autistic behaviour. Reported cases of this association are rare; however, I believe that it is not that uncommon. I can recall seeing three such cases. The following is an example.

Case Report: A male was born following a delayed labour and assisted delivery but recovered normally. Within 5 days he was found to be a restless baby with much screaming and difficulty in feeding. He walked at 12 months, but at 15 months he started to have temper tantrums. Subsequently, it became apparent that he had delayed speech. Later he developed overactive and disruptive behaviour, which eventually lead to his admission to a child psychiatry unit at the age of 3 years. He was diagnosed as having a profound language disorder with severe autistic traits, but was of potentially normal intelligence. Physical examination at this time showed no neurological abnormalities, but roughened skin on the cheeks and between the shoulder blades was noticed. Over the next few years there were many reports of poor social interaction, delayed speech with reversal of pronouns, mannerisms, inappropriate emotional reactions, resistance to change, and unusually good reading ability. A the age of 6 he developed epilepsy, which remained well controlled with anticonvulsants. At various times during his childhood he attended an ESN (M) day school, several private residential schools, and a school for autistic children.
At the age of 9 he was referred to me by the social worker because of difficult and aggressive behaviour. Physical examination revealed clear facial adenoma sebaceum, several areas of depigmented skin on the trunk and legs, and the previously recorded roughened areas between the shoulder blades. The family was advised of the possible diagnosis of tuberous sclerosis. Both parents were very intelligent and they had a normal daughter. The only significant feature in the family history was that the mother had had a mentally handicapped half brother who died at the age of 22 years with a tumour of the liver. Further physical examination of the family by a consultant geneticist revealed that the mother had a slight skin lesion in keeping with the diagnosis. The father and the sister appeared to be unaffected. The parents were advised of the significance of the findings, but had already decided to have no more children.

The patient has continued to present problems of management, especially aggressive behaviour, and still has many autistic features. He attends an Adult Training Centre and lives in a Social Services hostel.

The above illustrates not only the association of the two conditions but also supports the authors' conclusion that a suspicion of tuberous sclerosis should be aroused if autistic features and epilepsy coexist. It also suggests that history taking and physical examination in child psychiatry should always involve a genuine appreciation of genetic factors.

\section{Chelmsley Hospital \\ Marston Green \\ Birmingham B37 7HL}

B. E. Oliver

\section{Delusional Parasitosis}

SIR: Macaskill (Journal, February 1987, 150, 261263) reports the first case of a non-pharmacologically induced remission of delusional parasitosis. Hunt \& Blacker (Journal, May 1987, 150, 713-714) suggest that this was a mild form of the disorder, associated with clear precipitants. I report two further cases of spontaneous remission.

Case reports: (i) A 51-year-old housewife with no previous history of medical or psychiatric illness presented to a dermatology clinic with a one-month history of parasites in her hair. She described hearing them moving, and could feel them burying into her scalp. She produced a matchbox containing skin scrapings as proof. There were no obvious precipitants, although she was under chronic strain through coping with her demented mother. The dermatologist found no abnormality, and prescribed no treatment. However, he concurred with her suggestion of a brief holiday in Spain. On her return two weeks later she was seen by the psychiatrist. She said the parasites had now gone, but was certain they had been present. There was no evidence of 